\title{
ASSISTENCIA À PARTURIENTE: ALGUNS ASPECTOS PSICOSSOCIAIS
}

Doroty Leite Barbieri*

Maria Alice Tsunechiro*:

BARBIERI, D. L. \& TSUNECHIRO, M. A. Assistência à parturiente: alguns aspectos psicossociais. Rev. Esc. Enf. USP, São Paulo, 17(1):33-37, 1983.

A parturiente e o processo da parturição são encarados dentro do contexto psicossocial a fim de tornar o nascimento em ambiente hospitalar um ato mais humano. São apresentados alguns fatores que podem influenciar o fenômeno do parto $e$ o comportamento da parturiente como a internação hospitalar, reações emocionais $e$ sentimentos relativos ao parto entre outros.

É prática comum, desde há vários anos, a mulher dar à luz em ambiente hospitalar. A maternidade, dispondo de profissionais e equipamentos especializados, oferece condições para a utilização de tecnologia moderna e, com isso, proporcionar maior segurança para a mãe e para a criança.

No hospital, durante o trabalho de parto, a mulher recebe quase que exclusivamente cuidados de médicos e do pessoal de enfermagem, us quais na maioria das vezes lhe são estranhos. Para a parturiente, o ideal seria receber assistência de profissionais já conhecidos e, também apoio de pessoas do seu relacionamento mais próximo, como o marido.

ZIEGEL \& CRANLEY $^{9}$ afirmam que a parturiente deveria receber assistência de enfermeira que a conhecesse desde o pré-natal e que já soubesse de sua história, características de sua personalidade e circunstâncias familiares. Entretanto, no nosso sistema de administração hospitalar e de assistência à saúde vigente, é extremamente difícil à enfermeira conhecer previamente a parturiente e prestar assistência global no ciclo grávido-puerperal.

Nestas condições, geralmente a enfermeira tem o primeiro contato com a parturiente no momento de sua admissão no hospital. Sabe-se

\footnotetext{
* Enfermeira. Mestre em Enfermagem. Professor Assistente do Departamento de Enfermagem Materno-Infantil e Psiquiátrica da Escola de Enfermagem da USP — disciplina Enfermagem Obstétrica e Neonatal.
} 
que é importante estabelecer, desde o início, relacionamento interpessoal satisfatório entre o pessoal hospitalar e a parturiente; esta medida visa proporcionar melhores condições para a sua adaptação ao meio hospitalar, evitando que este se torne impessoal e frio.

Do mesmo modo, não podemos esquecer que a parturiente que assistimos na maternidade é uma pessoa que tem necessidades bio-psico-sócio-culturais. Os motivos que levam a mulher a procurar maternidade são vários, sendo o mais comum, a queixa de "dor de parto" em gestação a termo; além disso, é uma fase de grande desgaste psicológico. As emoções em relação ao trabalho de parto variam de mulher para mulher e são influenciadas por muitos fatores.

MALDONADO ${ }^{4}$ considera o parto como um processo psicossomático onde as características são determinadas por várias facetas do contexto sócio-cultural e da individualidade físico-psicológica da parturiente.

BETHEA $^{1}$ afirma que o reconhecimento das necessidades psicossociais da parturiente provoca mudanças na forma de atuar do pessoal hospitalar, tornando assim o parto uma experiência gratificante para a mulher.

Para a enfermeira, a percepção imediata das necessidades físicas e psicossociais nem sempre é fácil, pois depende da fase do trabalho de parto em que se encontra a parturiente e de seu estado emocional.

O fato é que a parturiente, além de toda a assistência técnica, precisa de apoio emocional. Para tanto, procuraremos evidenciar neste trabalho alguns aspectos da área psicossocial que podem influenciar o fenômeno do parto e o comportamento da parturiente. Esperamos que essa abordagem ajude a enfermeira a estabelecer um relacionamento satisfatório e perceber mais rapidamente os problemas, desde o momento da admissão e, com isso, favorecer o evolver do trabalho de parto e do parto propriamente dito. A percepção pela parturiente de que está sendo compreendida em suas manifestações de comportamento é fator fundamental para o êxito desse relacionamento.

Não pretendemos fazer considerações de ordem psicológica e sociológica mas apenas apresentar as variáveis mais freqüentes que podem influenciar na identificação da necessidade de apoio da parturiente como ser bio-psicossocial. Com isso, queremos alertar o pessoal hospitalar que assiste a parturiente que nem sempre as reações manifestadas por ela são devidas à "dor do parto", pois pode haver outros motivos que exacerbem essa sensação dolorosa ou que levem a parturiente a se queixar dessa dor, mesmo não estando presente.

Os fatores que apresentamos a seguir são aqueles observados ao longo de nossa experiência profissional na assistência à parturiente e também os abordados na literatura de enfermagem obstétrica ${ }^{1,3,6,7,9}$ e de psicologia relacionada à mulher no ciclo grávido-puerperal ${ }^{2,4,8}$. 
A internação hospitalar para a maioria das pessoas, assim como para as parturientes, significa separação da família, solidão, abandono, limitação da atividade, medo do desconhecido, entre outros.

Sendo a mulher o esteio da família, sua internação pode gerar certa desorganização familiar, principalmente se tiver filhos e não existir outra pessoa para cuidar deles e de sua casa durante sua ausência. Há ocasiões em que, no momento da internação, a parturiente demonstra essa preocupação ao perguntar sobre o tempo de sua permanência hospitalar. Por outro lado, não é raro a gestante que foi ao hospital apenas para se submeter a um exame ser internada sem que esse fato fosse previsto.

Em nosso meio, em hospital-escola ou beneficente, não é permitido à parturiente ficar com acompanhante durante o trabalho de parto e ela fica, quase sempre, aos cuidados de pessoas desconhecidas. Além disso, ao se dirigir para a maternidade, a parturiente nem sempre tem a companhia do marido; este, muitas vezes está ausente por motivo de trabalho, de viagem ou de abandono. Nesta ocasião, então, ela vem acompanhada de pessoa da família, amiga ou, por vezes, de pessoas estranhas ou mesmo sozinha. Nesta situação é mais freqüente a parturiente sentir-se abandonada e só.

Outros aspecto relevante é que para algumas parturientes esta é a primeira experiência de internação hospitalar; isto é válido tanto para primiparas como para multíparas, pois estas podem ter tido somente experiência de parto domiciliar. O hospital é sempre um ambiente estranho para ela e sua família.

Ao internar uma parturiente, é fundamental lembrarmos que a maioria é considerada pessoa sadia, porém a condição de estar grávida e em trabalho de parto a torna diferente dos individuos sadios; ela está exposta a maiores riscos em seu estado de saúde.

O fato da parturiente estar internada, apesar da condição de pessoa sadia, faz com que tenha limitação de algumas de suas atividades, tornando-a de algum modo, dependente do médico e do pessoal de enfermagem.

Essa dependência, porém, precisa ser controlada pelo pessoal da equipe hospitalar, levando-se em consideração que a parturiente é o elemento fundamental do processo da parturição. É importante que todos sintam e atuem como elementos de uma equipe e tenham objetivos comuns, ou seja, melhores condiçōes materno-fetais no trabalho de parto e no nascimento da criança.

Independentemente dos fatos relatados, certas reações podem ser geradas por preocupações relativas ao próprio trabalho de parto. É comum a parturiente ter medo das "dores" decorrentes da contração uterina e de morrer no momento do parto; preocupar-se, também, com o que vai acontecer com ela e com o filho; temer pela ocorrência de uma experiência traumatizante, quando já passou por essa situação em partos anteriores; ter receio de que o filho nasça a qualquer momento, 
por não ter noção do evolver de um trabalho de parto (pode ocorrer com a primípara, principalmente se for deixada sozinha). Outro fato que merece destaque é o temor que a maioria das parturientes têm dos procedimentos que são inevitáveis como: toque vaginal, enema, tricotomia e episiotomia. Às vezes o medo é tão intenso que a parturiente pode entrar em mutismo e com isso levar a enfermeira a uma percepção errônea dos seus sentimentos.

Convém lembrar ainda que experiências anteriores de internação hospitalar, por outros motivos, também influenciam no comportamento da parturiente.

A falta de expressão da dor não significa necessariamente que esta esteja ausente. Isto pode ser um condicionamento cultural. A maioria das parturientes experimentam sensação dolorosa com intensidade que varia desde desconforto ligeiro, sensação de pressão até dor intensa e sofrimento.

Não é raro existir manifestação de vergonha por parte da parturiente mais idosa ao ser admitida por uma enfermeira muito jovem, principalmente se ela tiver experiência de ter sido atendida, em partos anteriores, por "curiosas" que quase sempre são as mulheres mais idosas. Algumas parturientes verbalizam "vocês, tão meninas e já cuidando destas coisas ..." ou "poderiam ser minhas filhas..."; outras demonstram receio quando manifestam inclusive dúvida quanto à competência da profissional muito jovem.

O trabalho de parto é um período de transição: da espera de um filho à realidade de tê-lo; é uma situação de passagem de um estado a outro, cuja principal característica é a irreversibilidade — uma situação que deve ser enfrentada de qualquer forma. Pode haver sentimento de solidão e abandono no momento do parto, pois ela não pode transferir para outra pessoa a responsabilidade de "fazer nascer" o filho.

Para a parturiente, o parto é uma das experiências de vida mais significativa e importante: é o dia da chegada do seu filho. Pode ser um evento esperado, bem-vindo ou de alívio, o grande momento das respostas às perguntas que perduraram nove meses: a criança é perfeita? é menino ou menina? é parecido com quem? Pode ser também um evento terrível, de sofrimento do qual não se pode fugir, podendo ser considerado como um teste de resistência.

Antes de finalizar, ressaltamos que, ao admitir uma parturiente, não cabe à enfermeira fazer juizo de valores quanto à pessoa da parturiente se estiverem presentes agravantes morais.

Concluindo, citaremos NORONHA ${ }^{5}$ que faz a seguinte observação - do parto não resulta apenas um nascimento, mas quatro: nasce uma criança, nasce uma mulher para o papel de mãe, um homem para o papel de pai e nasce uma família.

Em suma, é importante considerar o parto dentro de um amplo contexto psicossocial pois significa o aparecimento de um novo ser humano e representa sempre uma esperança para a humanidade. 
Esperamos que a compreensão destes fatores influenciem positivamente na atitude da enfermeira diante da parturiente e do processo da parturição, tornando o nascimento um ato mais humano. Porém, não podemos nos preocupar apenas com a realização de um parto bem sucedido; o nascimento envolve todo um processo de vida.

BARBIERI, D. L. \& TSUNECHIRO, M. A. Assistance to the woman in labor: some psychosocial aspects. Rev. Esc. Enf. USP, São Paulo, 17(1):33-37, 1983.

The woman in labor and the natural parturition process are considered within a psychosocial context, in order to provide for childbirth in hospital environment a aspect more humanized. Some aspects are pointed out as to influencing the hospital process and the behavior of the woman in labor, such as: hospital admission, emotional reactions and feelings relatives to labor and delivery and others.

\section{REFERENCIAS BIBLIOGRAFICAS}

1. BETHEA, D. C. Enfermagem obstétrica básica. 3. ed. Rio de Janeiro, Interamericana, 1982. $363 \mathrm{p}$.

2. CORReA, F. K. Gravidez: aspectos psicológicos, sociais e complicações obstétricas. Ribeirão Preto, $1979.180 \mathrm{p}$. (Tese de Doutoramento - Faculdade de Medicina de Ribeirăo Preto da Universidade de Săo Paulo).

3. ISQUIERDO, N. Atribuiçăo da enfermeira obstetra na admissăo da parturiente em maternidade. Porto Alegre, 1976. 58 p. (Tese - Livre Docencla - Escola de Enfermagem da Universidade do Rio Grande do Sul).

4. Maldonado, M. T. P. Psicologia da gravidez, parto o puerpério. 2. ed. Petrópolis, Vozes, 1977. $118 \mathrm{p}$.

5. NORONHA, D. Mitos da gravidez: ser mãe é padecer (e crescer) no aqui e no agora. Psicologia Atual, São Paulo, 2(12):15-9, /s.d./.

6. REEDER, S. R. et alif. Contribuición de la enfermera al alivio del dolor durante el parto. In: - Enfermería maternoinfantil. Washington, OPS/OMS, 1978. cap. 16, p. 251-73.

7. SCHMIDT, M. J. \& FREDDI, W. E. da S. Preparo da gestante para o parto. Aulas teórico-práticas. Rev. Bras. Enf., Rlo de Janeiro, 28(1):15-25, jan./mar. 1975.

8. SOIFER, R. Psicologia da gravidez, parto o puerpério. Porto Alegre, Artes Médicas, 1980. $124 \mathrm{p}$.

9. ZIEGEL, E. E. \& CRANLEY, M. S. Enfermagem obstetrica. 7. ed. Rio de Janeiro, Interamericana, 1980. 